was kinked above an aberrant branch of the mesenteric artery (Spriggs and Marxer, 1937).

\section{Intussusception and Actinomycosis}

We have seen three cases of intussusception of the small intestine. In one the jejunum passed at intervals into the stomach through a gastro-enterostomy. This caused a burning scarified feeling which recurred on and off for four years. It was relieved by some foods, and always by a rest and holiday with general treatment. This patient has now been free of the sensation, and, at observations, of the intussusception, for six years. The second patient gave a four-years history of sudden nausea, vomiting, and pain, and on one occasion melaena. She had been treated for duodenal ulcer without benefit, and came to the clinic for investigation. Fortunately, an attack occurred in the $x$-ray room and the intussusception was seen. The infolding of the upper jejunum reduced spontaneously, and at operation was found to be due to a small adherent gland. Adhesions were separated, and there was no recurrence. In the third case, which is under observation, the terminal ileum passes into the caecum, with mild discomfort.

Actinomycosis involving the ileum occurred in a man of 28 who had had large amounts of fluid, containing the fungus, taken from the peritoneum before admission. Intensive treatment with iodide had given relief. The lesions of the intestine could be seen in the radiographs. With a quiet regimen and withdrawal of morphine the symptoms improved. A haemorrhagic cyst then developed about the pancreas after a trauma-namely, hitting the ground hard with a mashie, which caused acute pain. This was operated upon successfully. But after some months fresh pains developed, and a year later it was reported that death had followed repeated operations.

\section{Growths and Foreign Bodies}

Primary growths of the small bowel are rare, and are varied in nature. A short summary of those which have been observed is contained in a paper to which $I$ have referred (Spriggs and Marxer, 1937). Secondary growths are usually at the later stage of a general dissemination. Pressure or extension from a neighbouring growth is not uncommon. Pain may be reflected towards the root of the mesentery and up to the left hypochondrium.

In one patient a gall-stone caused acute obstruction. In two others tapeworm and roundworm respectively were detected in the terminal ileum by $O$. A. Marxer with the aid of radiographs. The symptoms disappeared with appropriate treatment.

\section{Summary}

The acute diseases of the small intestine include gastroenteritis, typhoid fever, and acute obstruction.

Most of the chronic disorders met with in practice are due to peptic ulcer and its treatment by anastomosis with the jejunum, or to mechanical interference with the lower ileum from inflammations or operations in that region. Patients in the second group have not infrequently been labelled colitics or neurasthenics. A detailed clinical and radiological study is needed to determine the nature and site of the lesion. If an exact diagnosis can be made much relief is given by medical means in most, and by surgery in others.

Chronic intrinsic diseases of the small intestine occurred in 3 per cent. of a series of 8,900 patients, and were, in order of frequency, diverticulosis, duodenal ileus, tuberculosis, regional ileitis, secondary growths, intussusception, primary growths, actinomycosis, and foreign bodies. If duodenal pouches are excluded the frequency of an intrinsic disease of the jejunum and ileum was 1 per cent.

The symptoms and treatment of each group are briefly reviewed.

\section{REFERENCES}

Anderson, J. H. (1929). Lancet, 1, 1347.

Boycott, A. E., and Dannant, G. C. C. (1907-8). J. Physiol., 36, 283 .

Brock, J. F. (1939). Lancet, 1, 72.

Cohnheim, P. (1904). Zancet, $1,72$. klin. Med., 52, 110

Crohn, B. B., Ginsburg, L., and Oppenheimer, G. D. (1932). J. Amer. med. Ass., $99,1323$.

Fraser, I. (1933-4). Brit. J. Surg., 21, 183.

Langdon-Brown, W. (1908-9). Clin. J., 33, 109.

Lloyd-Jones, O., and Liljedahi, E. M. (1934). Med. Rec., 139, 320.

Logan, A. H., and Brown, P. W. (1938). Proc. Mayo Clin., 13, 335.

Meulengracht, E. (1933). Úgeskr. Laeg., 95, 1257. (Reported in Lancet, 1935, 2, 1220.)

Short, A. Rendle (1932). Index of Prognosis, Bristol.

Spriggs, E. I. (1907a). Med. Chir. Trans., 90, 283. (1907b). Clin. J., 30, 222.

(1909). British Medical Journal, 1, 825 (1910). Ibid., $1,1216$.

(1931). Quart. J. Med., 24, 540.

(1937). Proc. roy. Soc. Med., 30, 1213.

and Marxer, O. A. (1919). Lancet, 1, 91.

(1920-1). Brit. J. Surg., 8, 18.

(1922). Lancet, 1, 725 .

(1925-6). Quart. J. Med., 19, 1

(1937). Lpool. med.-chir. J., 45, 159.

Wangensteen, O. H. (1937). Bowel Obstructions, London.

\section{INDUSTRIAL INCAPACITY AND MODERN MEDICINE*}

\author{
BY
}

\author{
DONALD STEWART, M.D., M.R.C.P.Ed. \\ Medical Officer, Metal Group, Imperial Chemical Industries \\ Limited
}

The greater part of incapacitating sickness in this country is probably due to factors over which industry has little or no control. We have to remember that the workman spends only one-third of his life at work, and that during the remainder of his time powerful influences having no direct connexion with industry can affect his health. We know, of course, that injury and occupational disease can result in absence from and incapacity for work, and that other industrial factors, such as long hours, poor lighting, noise, and fumes, may in themselves be a direct cause of sickness, but it is impossible with our present knowledge to estimate what proportion of the total sickness of any section of the population is due wholly or partly to such conditions.

\section{Incidence of Sickness}

There is great difficulty in obtaining any accurate figures of incapacitating sickness in our various towns and districts, and a similar difficulty in obtaining sickness rates in different firms and factories. In the majority of cases they simply do not exist. Speaking generally, however, there is an average absence from work among the insured population of Great Britain of ten days for men and twelve days for women annually, estimated to be equivalent to an entire year's work of some 600,000 persons. These figures do not cover those absences of three days or less for which sickness benefit is not paid, and they include not only industrial workers but commercial, domestic, and other employees.

In the recent report of the Department of Health for Scotland (1939) more accurate figures are available. The

* The second of two Milroy Lectures, delivered at the Royal College of Physicians, February 23 and $28,1939$. The first lecture was published in last week's issue, at page 963. 
average duration of incapacity in an insured population of about $1,800,000$ persons was approximately fifteen days, chronic invalidism among a small group-and this is a most significant fact-being mainly responsible for a high proportion of the total number of days lost.

In a group of some 12,000 workers in the Midlands the average incidence of sickness during 1938 was seven days for men and twelve days for women, and the figures for the past four years are given in Table II. These figures

TABLE II.-Sick Absence Rates in a Group of Workers employed in the Metal Industry (1935-8)

\begin{tabular}{c|c|c|c|c|c|c}
\hline \multirow{2}{*}{ Year } & \multicolumn{3}{|c|}{ No. of Employees } & \multicolumn{3}{c}{$\begin{array}{c}\text { No. of Days Lost per } \\
\text { Worker per Annum }\end{array}$} \\
\cline { 2 - 8 } & Male & Female & Total & Male & Female & Total \\
\hline 1935 & 7,317 & 2,683 & 10,000 & 7 & 11 & 9 \\
1936 & 7,498 & 3,018 & 10,516 & 7.9 & 12.6 & 9.2 \\
1937 & 8,455 & 3,016 & 11,471 & 8.7 & 11.8 & 9.8 \\
1938 & 8,908 & 3,272 & 12,180 & 7 & 11.8 & 8.2 \\
\hline
\end{tabular}

represent the incidence of lost time due to sickness generally, and are exclusive of specific occupational disease and accidents ; nor do they include sickness among the clerical and administrative staff. This absence occurred in a group of workers engaged in the same type of trade-the non-ferrous metal industry-but containing a large and varied number of occupations, from the heavy refining and casting of copper to the repetitive machining of the metallic parts that go to make up the modern zippfastener. These men and women live in different areas of the Midlands, mainly in the Birmingham district, but also in Wolverhampton, Manchester, Leeds, Sheffield, and Swansea. In the factories in each of these areas the incidence may differ, for a number of reasons. In some cases there may be a considerable annual labour turnover, because of the periodicity of commercial activity and trade conditions generally. (By "labour turnover" I mean the percentage of workers that leave in one year of those taken on during the year.) In a number of factories the percentage of older workers, of juveniles, or of married women may be higher than in others, and because of these and other factors no conclusions will be drawn from the figures at this time.

\section{Some Industrial Factors in IIl-health}

There is no doubt that work, and industrial conditions generally, have an effect on health. We all know how unemployment affects moral and physical strength. And, again, we understand the relationship of satisfaction in work to health. The lack of incentive in effort, no matter what the remuneration, frequently leads to loss of interest and to breakdown. But in addition to these general principles there are certain conditions within industry which have an effect on the individual that is often a most important background to the subjective signs of ill-health.

It is frequently said that the stress and strain of industrial life is greater now than it ever has been. But if one analyses this statement, is it really so? There seems to be much that can be said on both sides. I often wonder if the compensations of to-day do not outweigh the possible increase in such stresses. Conditions of work have improved. Opportunities for amusement and recreation are greater. Transport and travel services have opened a new vista to the people. Repetitive work has increased no doubt, and the worker is often described as "a $\operatorname{cog}$ in the machine"; but actually the present generation of girl seems to like repetitive work. It suits her, it is relatively well paid compared with domestic service, it gives her an opportunity to think her own thoughts and even to daydream, and her hours of work are limited. There is the additional fact also that young girls rarely consider such occupation as a life's work. For these reasons they are well content to take on jobs that would be thoroughly loathed by men and boys.

On the other hand, there has been a definite rationalization and concentration of industry within recent years. This is an age of big mergers. There is a tendency, therefore, to diminish the master-servant relationship which so often produced the highest form of faithful service and work. The feeling of insecurity is still frequently present, and especially so because of the large numbers of unemployed. There is a speeding up all round, and competition in trade tends towards " production at all costs" - often at the cost of health. The increased employment of women in occupations where marriage means loss of earning power raises for young people a conflict involving a most powerful instinct, and has hitherto received little notice as a probable factor in breakdown. Housing has become related to industry as never before, and the problem of the location of industry generally has a bearing on health. Factories are still being built in overcrowded areas with no consideration for the human problems involved. Sir Malcolm Stewart, in his last report as Commissioner for the Special Areas, recommended that no more factories should be allowed to open in the London area. He asked, in fact, that the State should openly intervene to control the location of industry and undertake the work of industrial slum clearance.

Travelling to work and travelling in general have become not only complicated and expensive in the large towns but more nerve-racking. In the London Passenger Transport area it has been calculated that in the year ending June, 1937, $£ 16$ 3s. was paid per family in fares; and $£ 817 \mathrm{~s}$. per family in Birmingham during 1936. But in a small town during a similar period only about $£ 2$ to $£ 3$ was paid. And then there is noise-the noise of buses, traffic generally, and of trains. It has been shown, for example (and I am now digressing somewhāt from my main theme), that in the carriage of a London tube train travelling at 30 m.p.h. the noise is such that an adult lion eighteen feet away roaring continuously would be inaudible. To escape into the country from the great cities is becoming increasingly difficult. With the demand for land by industry and speculative builders, how long will it be before the seven acres of playing fields per 1,000 of the population, which the National Playing Fields Association consider to be necessary, is realized?

The fact that many men and women have to travel long distances to work has also a direct bearing on their health. Early rising is necessary to get to work by eight o'clock. And so often this is accompanied by no breakfast, the worker being content, perhaps, with a hastily consumed cup of tea, sometimes heated up from the night before, and bread-and-jam, but more often just the tea alone. About 9.30 to 10 a.m., and again in the middle of the afternoon, the need is felt for nourishment and rest ; and if the employer is wise he arranges for a break of ten minutes in the middle of the morning and afternoon work spells, and also provides facilities for the worker to eat something brought from home or bought off a trolley, such as a hot drink of tea or cocoa or milk. In my own firm these desirable modifications have been introduced, and have proved to be of value in reducing fatigue, particularly in repetitive work among girls. At the same time output has not been diminished. 
Then there is the problem of the person in authority. By a lack of understanding and inherent inability to command, by personal defect in character or merely by sheer ignorance, such a person can make life a positive hell for those under him. And this holds good in all departments of industrial management, from the top downwards. Unfortunately such persons do exist to-day, and they are directly, although as a rule quite unconsciously, the cause of mental breakdown in many people. It should be noted, however, that such a breakdown may not always result in absence from work; it produces in some persons a permanent state of subfitness which is a true incapacity and as significant as the major physical disease. On the other hand, the man in authority who has understanding and some knowledge of the problems of human nature does much, and again unconsciously in many cases, to inspire confidence, to make work a real part of the art of living, and to produce directly that feeling of well-being and contentment so essential to full health.

And then there is a class of person who has frequent breakdowns in health because of nervous or neurotic tendencies. In complaining to the doctor they unconsciously stress physical symptoms that are not the real cause of their trouble. They react to the external stress of industry and occupation by the development of a nervous illness, or, if they do escape an actual breakdown, carry their symptoms with them throughout their working life. The anxiety state so frequently found cannot be regarded always as a neurosis, for it may be a reasonable reaction to the patient's mode of life, and industry may be in need of adjustment as much as, and often more than, the worker bimself.

Conditions of work-for example, the number of hours worked per week-also affect health. The extent of overtime for women and young persons is limited by law, but there is no legal limit to the number of hours that men over 18 years of age can work, although mutual agreements limiting the amount of overtime that can be worked per month have been made between some trades unions and employers' federations. Continuous night work also, which is prevalent in certain industries to-day, is a potential cause of ill-health. The strain of certain occupations in the heavy industries, such as metal casting and refining, excessive weight lifting, and outdoor work in all weathers, may also have a noticeable physical effect on certain men.

And then comes the question of lighting, heating, and ventilation, and comfort factors generally. In my experience lighting is more important than is often realized, and I have had occasion frequently to deal with complaints of eyestrain, headache, and general debility which have been directly caused by deficient or ill-designed lighting. Standards of lighting vary naturally for different occupations. On highly skilled fine work such as toolmaking, micrometers have to be read to a ten-thousandth of an inch and the work examined from all positions. For such work a high intensity of illumination is necessary, the light has to be localized, and there must be freedom from glare. On the other hand, for general labouring the intensity of illumination need not be nearly so high, and no local lighting is necessary; but there must be a reasonable illumination so that the work is safe. In this country there are as yet no generally accepted lighting standards as there are, for example, in the U.S.A.; but the Departmental Committee on Lighting in Factories has recently published a Report (1938) in which the work of standardization has been started. The good works engineer knows much about lighting because of its economic importance to production, and he may understand its significance in relation to the worker; but it often remains for the industrial medical officer to advise in some detail on such matters. For this reason, to take lighting still as our example, he must be able to use a photometer to back up opinion by evidence and to lay down suitable standards with the engineer for the various occupations in his factory. This is work that will repay well both in prevention of ill-health and in an all-round increase of efficiency.

\section{Occupational Diseases}

In many quarters the term "industrial medicine" has been taken to mean solely the study of occupational diseases to the exclusion of other aspects. It is therefore necessary to place such diseases in their true perspective in relation to industrial incapacity generally and to claim for industrial medicine a field of work and study which stretches far beyond the confines of disease.

In 1936 some $£ 555,000$ was paid out in compensation for occupational disease in the seven great groups of industries already referred to. This sum was paid to just under 20,000 cases, the bulk of which occurred in the mining industry as miners' nystagmus, beat-hand, and beat-knee. For cases of silicosis $£ 173,500$ was paid, giving a total of nearly $£ 730,000$. "Continued cases"that is, the cases carried over from previous yearsaccounted for 70 per cent. of this figure. Industrial injuries for which compensation was paid occurred in the same groups of persons to the extent of some 440,000 cases, or approximately to a number twenty-two times greater, the amount of money being paid out in compensation being nearly ten times as much.

But when one considers the incidence and cost of sickness among industrial workers generally some sense of proportion can be arrived at. It has been estimated that the money value of the work lost annually by employees for which national health insurance sickness benefit is paid cannot be less than $£ 100,000,000$ a year, without taking into consideration the dislocation in industry. This is twenty times more than the direct cost of injuries, and nearly two hundred times more than the cost of occupational diseases.

In my group of 12,000 workers industrial disease occurred during 1937 in only seven persons, who averaged a loss of thirty-seven days-all cases of dermatitis, and one of them was off for 105 days. The total amount of compensation paid in these cases was $£ 66$. In this particular industry the risks of occupational disease are few, because of the nature of the work, but they do exist ; for example, lead, chromium, solvents of all kinds, fumes, and toxic dusts. The co-operation of the employer and production managers and plant engineers with the medical service has done much to prevent its incidence. And one has only to study the Annual Reports of H.M. Chief Inspector of Factories to see that, comparatively speaking, the incidence of such disease in relation to the population at risk is low. Some 480 cases of poisoning were reported during 1937 (under Section 73 of the Factory and Workshops Act, 1907, or Section 3 of the Lead Paint Act, 1926), of which 141 were cases of lead poisoning, 183 of epitheliomatous ulceration, and 101 of chrome ulceration.

I do not suggest for one minute that industrial disease is relatively unimportant. Indeed, in many ways it is vitally important to some industries, and overshadows everything else-for example, in the potteries, in the dyestuffs industry, in certain coal-mines, and in the nickel- 
refining industry. Generally speaking, however, occupational disease is under control in this country-thanks largely to our present legislation and to the work of His Majesty's Medical Inspectors of Factories, whose contribution to preventive medicine within recent years has been but scantily recognized.

Two facts stand out in connexion with this subject. First of all, these diseases would not occur if certain chemicals were not used by industry, and for this reason they appear to be a high price to pay for production; secondly, however, it is the very nature of things that industry must progress, and that new materials, processes, and products must continually be evolved, if we as a country hope to keep pace with international trade. And this is one of the strongest arguments for the employment of an industrial doctor where specific hazards and risks do occur. In collaboration with the plant engineer and works manager he can be largely instrumental in preventing trouble, and he can safeguard the worker by periodic examination and by detailed attention both to the hygiene of the individual and to that of the factory. In this way alone can certain industries progress; plant and process can be made safe for the workman, personal ignorance about the potential danger can be largely dispelled, research can demonstrate toxicity, and the endresult can be of benefit all round-to the employer, who can market his product and achieve yet another triumph for science, and to the worker, whose health is adequately safeguarded.

\section{The Juvenile in Industry}

One of the most important contributions that the industrial medical officer can make to health generally is the supervision of juveniles in the factory. Medical examination on entrance is important, but it must be accompanied by a follow-up system if satisfactory results are to be obtained. Under law the examining surgeon has to carry out a first examination, and if he is dissatisfied in any way with his findings he can re-examine the "young person" before giving a final certificate of fitness. The type of examination to be carried out is laid down, and is an undoubted improvement on the state of affairs that existed before the new Factories Act came into force. From the medical point of view, however, this work loses much of its possible benefit because it does not allow for systematic follow-up examinations. To state that the child-for such workers are no more or less than children -is fit for certain work on entrance to industry is certainly of value; but what do we know about the child's condition after three or six months? How do we know that he has not been transferred to some job completely beyond his scope? And what do we know to-day about the effects of industrial environment on the juvenile who has been precipitated into industry straight from school?

Very often, of course, the boy or girl of 14 or 15 is completely grown up in outlook and, it may be, in habit. There is little he may not know about life, and from an early age he may have been in contact with a sordid reality that is seldom experienced by our own children. Such conditions frequently obtain in our large industrial cities. But many children are not so sophisticated. Any precocity that they may show is on different lines, and to them the new life is all too strange. Overnight they become adults almost; they are wage-earners-that in itself is a thrill; they make contact with many different types of worker-maybe to their detriment; and they become part of an industrial community with all its potential influences for good and evil. The wise employer understands this, and provides facilities which do much to smooth the way during the young worker's early days. But, even so, the medical man or woman who is fortunate enough to have the opportunity is in the position to do just that amount more than the layman which can be so effective. All his training and experience fit him for work of this description.

In my group we started a follow-up system on a definite plan only in July, 1937, seeing the juvenile on entry, and after one, three, and six months, and thereafter at six-monthly intervals. But even in this short time we know that we are on the right lines and that personal contact with the boys and girls, and the supervision of their growth and development, physical and mental, have been happy in their results. It is too early to make any dogmatic statements about the investigation-incidentally our scheme was introduced primarily to benefit the young person and not as a scientific experiment-but, nevertheless, even at this stage we have come to some conclusions. They like coming to talk to the doctor; the parents are becoming interested, and often discuss points with us; boys grow and develop physically more rapidly than girls; many boys lose weight during the first month, girls hardly ever; facilities in the works for games of all kinds after hours are patronized to a much greater extent than by adults; many of them pay as much as one-third of their weekly wage on transport to and from work; teeth need attention in nearly 30 per cent. of cases; and, what is curiously significant, the annual turnover in juveniles has been reduced by approximately 20 per cent. These and many other points are gradually being elucidated, and as by this time we have examined upwards of 600 different juveniles, many of them on frequent occasions, some estimate of the potential value of the work can be made.

\section{National Security and Industrial Health}

In these days the most important issue with which we as a nation are concerned is the degree of our national security and preparedness for war ; and no discussion of industrial incapacity and its relation to modern medicine would be complete without some mention of this fact. To bring about a state of security and to spend such large sums of money as have been voted have meant a great increase in activity in many industries. This has been accompanied by long hous of work and much fatigue. Over a short period of time-months or even a year-other things being equal, this need not take toll of health in the average man or woman. But in a state of war matters would change. Abnormal conditions of work would become those of every day, without hope of change. "Output at all costs" would be the slogan in a war dominated as never before by the machine. The occasional rush of business life would develop into a constant headlong skelter. And the man or woman in the factory would once again tend to become relegated to the background at the expense of production.

It took nearly a year of the great war for the Government to recognize the signs of human industrial fatigue and to realize that production was dependent utterly on man. How long will the period be in the next war? Surely now is the time to see that along with expert management and scientific research should go a parallel supervision of environmental working conditions, of the welfare of labour and conditions of work, and of the immediate health risks and hazards which arise. Of all things the one to be prevented is the risk of industrial fatigue in a future emergency. Yet to what extent is this being considered to-day and being undertaken by the 
country as part of its defence policy? In some industries there is a well-established regard for human relationships exemplified by progressive welfare schemes and working environment, and a knowledge of health problems; but unfortunately these schemes affect only a proportionprobably not more than one-third-of our industrial population. Much work has got to be done, and much of it by the medical profession, because the problem is essentially one of preventive medicine along lines that, quite frankly, have hitherto been unexplored.

\section{The Need for Knowledge of Industrial Life}

The subject of these lectures is so comprehensive that it has been impossible in the time at my disposal to cover all the ground. There are many other points which I should have liked to discuss-for example, the problem of the epileptic, the return to work of the tuberculous patient, the place of the diabetic in industry, and the many aspects of research into the potential toxicity of substances and processes. And then there is that part of the industrial medical officer's work which has to do with examinations within the factory clinic, but which has been referred to in some detail on another occasion (Stewart, 1938); examination of applicants for employment, of employees before transfer to hazardous work, or of those who suffer from disabilities such as heart disease, hernia, or malnutrition, and who need to be kept under periodic medical supervision. But before I finish I should like to emphasize as strongly as I can one further point-namely, the need for a fuller knowledge of industrial life on the part of the medical profession to-day and for a knowledge of the patient as a man or woman with a vivid background of work. If we agree that industry can contribute to health as well as to disease, then the more fully we teach that the better. In a number of postgraduate schools, notably the London School of Hygiene, D.P.H. and other students are given an opportunity to learn something of the physiology and psychology of work; but so far the undergraduate has been restricted to a brief study of industrial diseases, and that was recommended by the General Medical Council only a year ago.

And again, some understanding of the needs of the worker can have an effect on hospital policy. The man or woman in the factory or in business who cannot afford to do otherwise than attend hospital for advice and treatment must do so in working hours in order to see the specialist; and by doing so he loses time and wages. Is it not possible that the frequent long wait in hospital could be reduced by the introduction of an appointment system, or even that hospitals in busy industrial districts could provide evening clinics? Further consideration of these two points is urgently required.

Then there is the return of the sick man to work. His rehabilitation is often as important as that of the man who is severely injured. In this, above all things, the medical practitioner can be of the greatest help to his patients. For him a knowledge of industrial medicine is not so immediately important as a general recognition of the common sociological facts of life, an understanding of the significance of housing, feeding costs, labour conditions, wage rates, and the like; all these form what is in reality an essential background to the medicine of our generation.

\section{Conclusion}

I wish to plead once again for further consideration of many of the points which $I$ have raised. . My appeal must first of all be to the employer, be he large or small, to set up for himself some form of medical service. And may I say now that the issue is not primarily one of expense. I believe, and many employers believe, that medical services in industry are first and foremost a good investment and not a philanthropic institution. The preservation of the health of the worker is as essential to industry as the maintenance of the machine; and hand in hand with production research must go planning for health. There must be a further infiltration of medical thought into industrial management, and this can only be brought about by a direct effort on the part of our profession. But the effort to be effective must be put into the language of industry, and above all must be practical in its basis.

Labour management to-day is more and more calling in the help and advice of doctors on all sorts of matters affecting the worker. We have seen some of the ways in which, within my own experience, this help has been given. And we have seen, too, that the assistance required is not by any means always that of the doctor within the factory. Co-operation of general practitioners, of public health services, of medical and surgical specialists, and of hospital authorities is vitally necessary. The worker's labour is his means of livelihood. His hands and his health are his capital. Livelihood can be preserved by industry, but health and capacity for work are traditionally preserved by us as a profession.

\section{BIBLIOGRAPHY}

Amor, A. J. (1936). Industr. Welf., 18, No. 216, 20

Bashford, H. H. (1938). Proc. roy. Soc. Med., 31, 185

Bevin, E. (1937). British Medical Journal, 2, 610.

Bridge, J. C. (1934). Lancet, 1, 471.

Buchan, J. J., and Stewart, D. (1938). Publ. Hith. 51, 163.

Collier, H. E. (1936). British Medical Journal, 1, 214.

Collier, H. E. (1936). British Medical Jo

Collis, E. L., and Greenwood, M. (1921). The Health of the Industrial Worker, London.

Crowden, G. P. (1937). J. roy. san. Inst., 58, 281.

Culpin, M. (1937). Med. Off., 57, 117.

- (1938). Ment $\mathrm{H}$ yg. London, 47.

Department of Health for' Scotland (1939). 7th Ann. Rep., H.M. Stationery Office, London.

Departmental Committee on Lighting in Factories (1938). 4th Rep. H.M. Stationery Office, London.

Factories Act (1937). H.M. Stationery Office, London.

Garland, T. O. (1936). Human Factor, 10, 23, 66, 99, 142, 183.

Halliday, J. L. (1935). British Medical Journal Supplement, 1, 86

Health of Munition Workers Committee (1915-17). Reports and Memoranda, H.M. Stationery Office, London.

H.M. Chief Inspector of Factories, Annual Reports. H.M. Stationery Office, London.

Home Office Welfare Pamphlets, Nos. 1-8. H.M. Stationery Office, London.

Hyde, R. R. (1936). Industr. Welf., 18, No. 216, 13.

Industrial Health Research Board (1938). Ann. Rep., H.M. Stationery Office, London.

(1919-38). Numbered Reports 1-83, H.M. Stationery Office, London.

International Labour Office. Bibliography of Industrial Hygiene (Quarterly), Geneva.

(1934). Occupation and Health, Geneva.

Lane, R. E. (1936). Lancet, 2, 206.

(1937). British Medical Journal, 2, 608

Ling, T. M. (1936). Lancet, 1, 1274, 1333.

(1937). Recent Advances in Industrial Medicine and Hygiene, London.

(1938). Med. Pr., 197, Suppt. 1.

Lockhart, L. P. (1934).' Lancet, 1, 825. (1935). Med. Ann., 266, Bristol.

(1937). British Medical Journal, 2, 605.

(1938a). Med. Pr., 197, Suppt. 3.

(1938b). British Medical Journal Supplement, 2, 378.

Maling, T. (1939). Industr. Welf., 21 , No. 241,8.

Mummery, N. Howard (1936). P̈ractitioner, $137,280$.

Munro, D. (1936). Practitioner, 137, 270.

P E P (1937). Report on British Health Services, 65, London.

Schilling, R. S. F. (1938). Private Report on Juveniles.

Smith, May (1937). British Medical Journal, 1, 503.

Stewart, D. (1936a). Lancet, 2, 609.

(1936). Practitioner, 137, 334.

(1939). Lancet, ï, 129.

Trumper, H. B. (1932). Private Reports.

Vernon, H. M. (1936). Accidents and their Prevention, Cambridge. ridge. 